\title{
A televisão após a hecatombe ${ }^{1}$
}

\section{Arlindo Machado}

\section{Resumo}

Uma velha questão, que remonta aos tempos de Adorno, refere-se à possibilidade da televisão vir a ser um espaço de experimentação e criatividade. 0 programa italiano Cinico TV, de Ciprì e Maresco, dá uma resposta radical a essa pergunta. Sem fazer nenhuma concessão aos padrões institucionais e industriais da televisão, Cinico traz à cena, num preto e branco lúgubre, um mundo que parece $o$ day after de uma hecatombe nuclear, habitado por uma galeria de personagens absurdos, um tanto escatológicos, com um sotaque siciliano e plebeu quase ininteligível, num cenário de ruínas, dejetos e prédios inacabados e abandonados. 0 programa é concebido como uma intervenção pirata na televisão. 0 artigo discute a decadência da televisão italiana e a resposta vital que lhe dá Ciprì e Maresco. Cinico TV foi uma demonstração de que a televisão pode ser outra coisa, pode arriscar-se em direção a um audiovisual de insubmissão ao gosto padronizado, um audiovisual de expressão de inquietudes não catalogadas, de modo a provar que há também vida inteligente na tela pequena.

\section{Palavras-chave:}

Cinico TV. Televisão experimental. Televisão e arte. Televisão italiana.

\section{Arlindo Machado | arlimach@uol.com.br}

Possui graduação em Letras Português e Russo pela Universidade de São Paulo (1977), mestrado em Comunicação e Semiótica pela Pontifícia Universidade Católica de São Paulo (1983) e doutorado em Comunicação e Semiótica pela Pontifícia Universidade Católica de São Paulo (1987). Atualmente é professor doutor da Universidade de São Paulo e professor titular da Pontifícia Universidade Católica de São Paulo. Tem experiência nas áreas de Artes e Comunicação, com ênfase em Estética e Linguagem do Vídeo, atuando principalmente nos seguintes temas: artes eletrônicas, arte e tecnologia, vídeo-arte, imagem eletrônica, teoria da comunicação e televisão de qualidade

\section{Introdução}

A televisão é normalmente praticada e pensada como o lugar por excelência do entretenimento leve e descompromissado, o espaço do espetáculo pueril, em geral voltado a um cotidiano anódino, diante do qual o cidadão comum pode relaxar-se depois de um dia ou uma semana de trabalho duro. Ao contrário de outros meios e artes, poucas são, em televisão, as experiências de risco, capazes de levar as possibilidades expressivas desse meio para além dos seus limites institucionais. Exatamente por essa razão, os intelectuais de formação mais tradicional (Adorno é certamente a referência mais óbvia) resistem à tentação de vislumbrar qualquer alcance estético nos produtos televisivos, produtos esses no geral fabricados em escala industrial para uma massa indiferenciada e pouco seletiva. No modo de entender desses intelectuais, a boa, profunda e densa tradição cultural, lentamente filtrada ao longo dos séculos por uma avaliação crítica competente, não pode ter nada em comum com a epidérmica, superficial e descartável produção em série de 
objetos comerciais de nossa época; daí porque falar em criatividade ou qualidade estética a propósito da produção televisiva só pode ser uma perda de tempo.

Mas, de repente, surge na televisão italiana - e justo na italiana, considerada uma das piores do mundo - uma experiência singular e extraordinária de televisão, uma experiência, pela primeira vez, radicalmente autoral, tanto no sentido de que constrói um estilo próprio e uma visão pessoal de mundo, como também no sentido de que a assinatura dos seus dois autores aparece na primeira cartela de abertura do programa, como a dos pintores aparecia no pé do quadro. Trata-se de Cinico TV, "de Ciprì e Maresco", como aparece na primeira cartela, referindo-se aos seus criadores Daniele Ciprì e Franco Maresco. 0 programa esteve no ar de 1989 a 1993, primeiro pela Televideo Market (TVM), de Palermo, e depois em horário nobre pela rede nacional Radio e Televisione Italiana (RAITRE), além de posteriores especiais e contínuas reprises, sempre acompanhado por uma legião de fãs fidelíssimos em toda Itália. Foi considerado pelo cineasta Bernardo Bertollucci a única coisa inteligente que aconteceu no audiovisual italiano nas últimas três décadas.

A primeira coisa que chama a atenção nesse programa é a radical opção pelo preto e branco (jamais entra cor no programa). Mas não um preto e branco qualquer. Pelo contrário, através do uso sistemático de um filtro dégradé, que amplia os contrastes nas partes mais altas do quadro, as nuvens são exageradamente carregadas, dando a impressão de que uma tempestade iminente vai desabar sobre as cabeças dos protagonistas. Tudo é construído como se fosse uma interferência pirata na televisão. Tanto os planos iniciais e finais do programa, como as passagens entre os vários sketches, são constituídos pelo "chuvisco" característico da televisão fora do ar. De repente, quebrando todo o glamour espetacular e multicolorido do fluxo televisivo, entra no ar um objeto estranho, assustador, com uma visualidade que nada tem a ver com aquilo que se entende por televisão, expondo as vísceras de um punhado de personagens terminais, horrorosos, patéticos, num cenário de ruínas que evoca uma paisagem após uma hecatombe nuclear. Dizem os especialistas que se 0 mundo fosse submetido a uma guerra atômica, os únicos seres vivos que sobreviveriam seriam as baratas. Aqui temos um cenário após o cataclismo final, onde as baratas sobreviventes foram metamorfoseadas em formas humanas ou semi-humanas, contrariando Kafka, que imaginou, em seu Die Verwandlung (A Metamorfose), a história de um homem que se transforma em inseto.

Tudo começou um pouquinho antes, em 1986, no canal TVM, de Palermo, capital da 
província de Sicília, como se sabe, a região economicamente mais pobre da Itália, além de berço do banditismo organizado, a Máfia. A TVM foi uma das primeiras televisões livres da Sicília, inclusive também da Itália. 0 movimento das rádios e televisões livres na Europa, que sucede 0 anterior movimento das rádios e televisões piratas, visava se contrapor ao chamado monopólio estatal das ondas eletromagnéticas, ou seja, à concentração de todo poder de emissão radiofônica e televisiva nas mãos exclusivas do governo nacional. Num primeiro momento, era um movimento de contestação, liderado principalmente pelas forças de esquerda, mas, num segundo momento, esse movimento serviu de aríete para as empresas comerciais de comunicação pressionar os governos em prol de uma abertura para as rádios e televisões privadas. Depois de vários enfrentamentos e mudanças, muitas televisões livres foram legalizadas e transformadas em televisões comunitárias locais, como foi o caso da TVM. Após a legalização, esse canal se dedicou principalmente à realidade siciliana, mas para sobreviver, uma vez que não era uma televisão pública, nem estava na rota dos grandes anunciantes, mantinha vários programas de tele-vendas (daí o nome Televideo Market). Foi nesse canal que Ciprì e Maresco, ambos nascidos em Palermo, puderam realizar seus primeiros experimentos com televisão, através de programas dirigidos a jovens, emissões de jazz (uma paixão dos dois) e até mesmo paródias dos programas de tele- vendas. Em troca desse trabalho, a TVM lhes emprestava câmeras e lhes dava acesso às ilhas de edição para que eles pudessem realizar os seus próprios trabalhos experimentais. Assim, eles tiveram a oportunidade de criar, de maneira inteiramente independente, vários ensaios de curta duração que, eventualmente, também podiam ser exibidos nos intervalos entre os programas da TVM. Esses curtos já lidavam, de forma ao mesmo tempo cínica e cômica, com os problemas da comunidade palermitana, como a pobreza, a violência, a solidão, o abandono, 0 crime organizado e o caos urbanístico da cidade. Foram esses curtos que deram origem à ideia de Cinico TV, um programa de tipo fragmentado, constituído de pequenos sketches, depois juntados em edições diárias de cinco a dez minutos (salvo algumas exceções mais longas), que foram originalmente exibidos na TVM.

Em 1990, os jornalistas Didi Gnocchi e Mimo Londezzo, que realizavam um programa para a RAI-UNO, Isole Comprese (Ilhas Comprimidas), uma espécie de censo geográfico da Itália, mas também uma viagem através das televisões livres italianas, interessaram-se pelas emissões de Ciprì e Maresco no canal TVM e os convidaram a participar do programa. Mas os dois autores realizaram poucas contribuições para Isole Comprese, pois muito rapidamente foram censurados e despedidos, em razão de uma emissão que se referia explicitamente a Silvio Berlusconi, o Big Brother da Itália, controlador de todos os meios de comunicação públicos e 
privados, e ainda por cima, primeiro ministro do país (na Itália, equivalente a presidente). Nesse sketch, intitulado A Silvio, o personagem ciclista de Cinico TV, Francesco Tirone, aparece sentado diante de um aparelho de televisão, com a imagem de Berlusconi ao fundo, enquanto uma voz over lhe pergunta: "É verdade que Berlusconi quer comprar a Sicília?"” E Tirone, com um forte acento siciliano, lhe responde:

\footnotetext{
Berlusconi pode comprar a ilha inteira, ele é milionário e ninguém 0 pode impedir, ninguém pode detê-Io, nem mesmo Onassis com toda a frota naval. Creio que Berlusconi me vigia por radar, creio que ele me segue, me vê, controla todo mundo. Para mim, Berlusconi é mais poderoso que o papa, pois controla a televisão de todo o mundo. Berlusconi existe em todas as partes, está nas nuvens, no ar, em todas as partes do mundo, na água, no meio das tempestades.
}

Nesse mesmo ano, alguns sketches de Ciprì e Maresco foram apresentados em Fuori Orario (Fora de Horário), dirigido por Enrico Ghezzi ${ }^{3}$, um programa noturno da RAI-TRE dedicado a filmes e vídeos insólitos. Finalmente, a partir de 1992, Cinico TV começa a ser exibido dentro do programa $B l o b$ (nome extraído de um filme americano de terror classe B), também dirigido por Ghezzi na mesma rede pública. Blob é um programa de cerca de uma hora de duração, que é exibido (inclusive ainda hoje) no horário nobre das nove horas da noite e se dedica à crítica (às vezes implacável) da televisão italiana, focalizando o que foi ao ar nos dias anteriores (FAVA, 1993). Muito adequadamente, Aldo GRASSO (1992, p. XXIX) o classifica como um exemplo de meta-televisão, a televisão que se elege a si mesma como objeto de reflexão. A partir de então, Cinico TV passa a se chamar Blob-Cinico TV e se constitui como um programa dentro de outro programa, sem perder, entretanto, sua independência, suas características próprias e a sua intenção de aparecer como uma interferência pirata na televisão.

Cinico TV foi um programa sui generis, à margem de qualquer formato de televisão conhecido. Sem nenhuma explicação, a televisão saía do ar por alguns segundos, ficava na tela apenas 0 "chuvisco" típico de "fora do ar" e entrava então uma galeria de personagens absurdos, um tanto escatológicos, com um sotaque siciliano e plebeu quase ininteligível (pelo menos os personagens que falavam, pois alguns eram mudos, outros gagos, alguns afásicos ou catatônicos e só balbuciavam frases incompreensíveis). Tudo isso num preto e branco lúgubre, numa estranha periferia de Palermo (a parte central da cidade nunca é mostrada, muito menos o seu conhecido

Todas as citações de diálogos do programa, bem como as citações retiradas de textos publicados em língua estrangeira são de tradução nossa.

Enrico Ghezzi, além de diretor de televisão, é também um intelectual e estudioso dos fenômenos da comunicação de massa com muito prestígio na Itália. Dentre seus inúmeros trabalhos publicados, destacam-se II Mezzo è l'Aria (1997) e Paura e Desiderio. Cose (Mai) Viste (2003), importantes contribuições para se entender a mídia contemporânea. 
balneário mediterrâneo), em meio a carcaças de edifícios semi-construídos e abandonados, ou a depósitos de lixo e dejetos de construção civil, ou ainda no interior de cabanas arruinadas e vazias. A solidão é absoluta, quase metafísica, nunca há gente nas ruas, exceto aquele sub-lumpesinato aniquilado e sem saída, não mais que uma dúzia de zumbis que arrastam seus trapos (pelo menos os que estão vestidos, pois, na maioria das vezes, estão nus ou seminus) num cenário de destruição absoluta. É o outro lado do capitalismo avançado, global e tecnológico, o lugar onde foi despejado tudo o que não deu certo e para onde migraram todos aqueles que fracassaram.

\section{Embora os episódios de Cinico TV fossem} esteticamente apurados, como veremos à frente, Cìpri e Maresco não tiveram a preocupação de produzir programas com "controle de qualidade", tecnicamente acabados segundo um princípio industrial. 0 programa tinha uma aparência trash, embora não ficasse só nisso, como em outros exemplos internacionais parecidos apenas na superfície. No começo usavam o VHS, depois passaram ao Umatic e só quase ao final captaram com Betacam. Nunca usaram luz artificial, só a ambiente. No total, produziram 49 programas, todos eles realizados nos cafundós de Palermo e enviados através de cassetes a Roma, para exibição na RAI-TRE. Cada vez que chegava um cassete, o pessoal da produção de $B l o b$ tremia nas pernas, só de imaginar o que poderia estar chegando!

\section{Pobre Sicília}

0 sul da Itália tem sido considerado, pelo menos pelos italianos do norte, como uma região atrasada e sem nenhuma inclinação aos estandartes de progresso. Seus habitantes são estigmatizados como camponeses ignorantes, corruptos e mafiosos. A Máfia surge nessa região no século XIX, na forma de clãs familiares altamente organizados, que se dedicam ao crime e ao exercício autônomo de suas próprias leis, sob o amparo (ou negligência) do Estado, da igreja católica e dos meios de comunicação. Lá foi a terra do famoso bandido Salvatore Giuliano, que tinha fama de roubar dos ricos para dar aos pobres, mas sabidamente servia ao mesmo tempo ao governo e à Máfia. Por outro lado, a redução da produção agrícola logo depois da Segunda Guerra e 0 surgimento da Máfia como um fenômeno tipicamente rural geraram grandes migrações de populações camponesas aos centros urbanos do sul da Itália. A cidade de Palermo cresceu caoticamente, sem nenhum plano urbanístico. Ao mesmo tempo, a dificuldade de ocupar os edifícios do centro, por causa dos danos causados pelos bombardeios durante a Guerra, provocou uma caótica proliferação de construções e autoconstruções de imóveis nas zonas periféricas de Palermo, sem nenhuma infra-estrutura, e grande parte dessas construções nem chegaram a ser terminadas, ficando abandonadas, como se fossem fantasmas desvairados. Essa periferia serviu também de depósito a céu aberto para despejo das ruínas da Guerra: edifícios 
condenados, indústrias arruinadas e falidas, cemitérios de trens e automóveis, valas comuns onde os mortos eram enterrados em massa. É nesse cenário desolador que se passam os antiacontecimentos de Cinico TV.

Na década de 1980, quando Ciprì e Maresco se conheceram, as ruas de Palermo eram palco de permanentes enfrentamentos das organizações criminosas com a polícia, o exército e entre elas mesmas. 0 saldo era sempre uma infinidade de mortos e feridos de todos os lados e mesmo de parte da população civil que não tinha nada a ver com isso. Nadando contra a maré, Ciprì e Maresco criam um cineclube chamado Rosebud (referência ao famoso trenó de Citizen Kane), onde diariamente projetavam os clássicos do cinema para o público do bairro. Em uma entrevista sobre os seus primeiros anos de trabalho, Maresco conta:

Em uma zona morta da cidade, habitada por excluídos e delinquentes, nós projetávamos o novo cinema alemão, o cinema clássico, Stroheim, Bergman e tínhamos um público que raramente superava os cinco espectadores. Era preciso superar não apenas uma barreira mental, mas também os problemas práticos, na medida em que muitas vezes havia cinco mortos por dia e os helicópteros sobrevoavam permanentemente 0 bairro, o que desanimava ainda mais os poucos espectadores potenciais. ${ }^{4}$

Cinico TV é uma abstração desse cenário urbano, político e social da cidade de Palermo. No programa, Palermo se transforma numa cidade metafísica, lembrando certos cenários surrealistas de Magritte e de Chirico, onde tudo o que acontece ultrapassa os limites da razão. Permanentemente coberta de nuvens carregadas, Palermo aparece sempre imóvel, muda, surda, habitada por alguns poucos seres terminais, também eles paralisados, esperando passivamente a chegada do Juízo Final. Esses personagens, quase sempre seminus ou quase nus, alguns com defeitos físicos, aparecem se arrastando lentamente entre os dejetos, sem sequer lamentar a sorte ou emitir um gemido de dor, mas com uma tristeza infinita e uma desolação sem cura. A única coisa que se move, que fala sem parar, que tenta retirar esses personagens e cenários de seu torpor, é a televisão, é a equipe de Cinico TV, histriônica como se supõe que deve ser toda televisão, tentando inutilmente arrancar algum depoimento significativo ou emocionante desses trapos humanos.

Curiosamente, não há mulheres em Cinico TV. Embora muitos personagens lamentem o fato de nunca terem conseguido uma companhia feminina e frequentemente confessam que gostam de ficar espiando os casais fazerem amor, a mulher está fisicamente excluída desse universo. Há várias cenas de estupro, mas a vítima nunca aparece, ou quando aparece é visivelmente um homem travestido de mulher. Mas mesmo o estupro, quando acontece, é 
mais um ato banal de violência por si só, frio e mecânico, sem qualquer motivação erótica ou prazerosa. Conforme segreda Maresco (2009), "esse era um mundo onde não podia haver desejo, não podia haver Eros". Nada pode ser mais trágico que um mundo totalmente monossexual, pois se pelo menos fosse homossexual, haveria ali algum afeto. Na Palermo de Cinico TV, todos estão irremediavelmente abandonados, ilhados em sua própria solidão, não havendo horizonte para qualquer espécie de amor, afeto ou prazer, nem sequer companheirismo. Pior ainda: a impossibilidade do erotismo homem/mulher, conforme assinala Maresco (2009), significa a impossibilidade da esperança, a impossibilidade da continuidade da espécie, o fim do humano.

Cinico é um programa cruel, que faz rir pelo absurdo das situações, mas a sua comicidade é trágica. Logo nos damos conta de que estamos rindo da desgraça humana e contemos imediatamente 0 riso, envergonhados. Ciprì e Maresco ironizam o siciliano e 0 italiano em geral, um povo que, embora cultuado como 0 berço da civilização renascentista e moderna, hoje elege gente como Berlusconi e os famosos "pianistas" do congresso nacional e vê a pior televisão do mundo. Mas a fábula não se restringe apenas ao feudo italiano, ela tem alcance mais universal e se aplica a qualquer lugar do mundo onde a marginalidade é radical, a solidão é sem saída e a impossibilidade de mudança é fatal. Há algo aí do teatro do absurdo, de Pirandello a Ionesco, passando pelo Camus de La Peste, mas principalmente por Samuel Beckett, de quem Ciprì e Maresco admitem uma filiação incontestável. 0 trágico bestiário de Cinico TV passa a vida toda inutilmente esperando Godot. Conforme Maresco (2009):

0 que seguramente 0 público mais atento entendeu é que nós não apenas levávamos um conteúdo diferente, uma Sicília diferente, mas também levávamos uma linguagem diferente. Era uma linguagem como a do teatro que naquela época se chamava beckettiano; o teatro do uso do espaço, do território, como nós fazíamos.

De fato, o mundo de Cinico é absolutamente parado. Os planos são abertos e fixos (não há mais que meia dúzia de panorâmicas em toda a série; nenhuma zoom), lembrando o cinema mudo, até mesmo no uso de um difusor que obscurece as bordas do quadro. A paisagem não se mexe, as nuvens são estáticas, as ruas vazias, os trens desabitados, nem mesmo as folhas das árvores tremulam ao vento. Ao fundo, uma visão meio fora de foco da cidade de Palermo paralisada, que poderia ser qualquer outra cidade. Os personagens parecem viver fora do tempo, com um olhar fixo perdido em direção a algum ponto enigmático do universo. Estão quase sempre rígidos como uma estátua, com exceção dos trechos em que dançam alguma música obscura dos anos 1920 ou 30, com movimentos catatônicos ou robóticos, ou quando manifestam algum tipo de espasmo, com se estivessem sofrendo algo como um ataque epiléptico. Emitem murmúrios afogados, gritos mudos, 
desafinam quando fingem que cantam, algumas gargalhadas são histriônicas, mas bruscamente interrompidas. Falam apenas para a televisão, quando são entrevistados, pelo menos os que falam, pois muitos nem falar conseguem. Cospem muito frequentemente, uns nas caras dos outros, mas em geral cospem para cima, para que o cuspe caia na própria cara.

\section{Uma paródia da televisão}

A televisão italiana sempre foi um espaço de disputas por poder e controle político. Silvio Berlusconi, por ser o primeiro ministro da Itália durante três mandatos, controla os três canais públicos nacionais, mas também é o proprietário do império Mediaset, além de deter 0 controle dos principais meios de comunicação privados da Itália e da Europa, e ainda ser dono de bancos e de empresas de entretenimento, presidente do AC Milan, um dos principais times de futebol do país, e como se isso tudo não fosse suficiente, é frequentemente acusado de conexões com a Máfia. Foi citado pela revista Forbes como o homem mais rico da Europa, com uma fortuna estimada em 12 bilhões de dólares. As estatísticas demonstraram que Berlusconi, em sua fase áurea, controlou cerca de $98 \%$ da audiência italiana e por isso sempre ganhou as eleições. Ele é também uma das vítimas principais dos ataques de Cinico $T V$. Num dos episódios, os irmãos Zucato (Pietro e Francesco) abrem um processo contra Berlusconi para pedir uma indenização de um bilhão e cem milhões de liras por ter embrutecido 0 irmão mais jovem, Marcelo, que se tornou um débil mental de tanto ver os programas das televisões do primeiro ministro. Isso só foi possível porque a RAI-TRE, que exibia Cinico, é a rede que sofre menos influência de Berlusconi, por estar nas mãos da oposição (na Itália, as redes públicas de televisão são distribuídas entre os principais partidos). Não por acaso, ela é, dentre as três redes públicas, a primeira que Berlusconi cogita privatizar.

Cinico é ostensivamente uma paródia crítica dessa televisão que os italianos são obrigados a engolir diariamente. Todos os ingredientes da televisão estão lá: as entrevistas, que não servem para nada, pois nem os repórteres sabem o que perguntar, nem os entrevistados têm algo a dizer; os intervalos, que também não têm nenhuma função, a não ser interromper o fluxo televisivo, pois não há nada a ser vendido nos breaks comerciais; a estrutura seriada, que só serve para repetir ad infinitum o conhecido calvário dos pobres diabos da periferia de Palermo. Aqui ou ali, esboça-se uma infeliz réplica de um videoclipe, com a voz quase inaudível do pretenso "cantor"; performances "musicais" patéticas, que estão abaixo de qualquer programa de calouros; um personagem que representa as fezes de um mendigo ou uma camisinha de quinta categoria usada por um casal gay. E, sobretudo, impõe-se, o tempo todo, a voz autoritária da televisão, a voz over de um entrevistador sempre invisível (interpretado por Franco Maresco), como se fosse 0 deus beckettiano, gritando contra os 
indigentes, sem nenhuma piedade para com os miseráveis expostos voyeuristicamente diante da câmera, sempre em busca de temas sensacionalistas, como um homem-bomba, um assassinato ao vivo, um suicida potencial deitado nos trilhos de trem, à espera da locomotiva (que sempre se atrasa e quase nunca chega).

0 tempo, em Cinico, é controlado de uma maneira contraditória. Como costuma acontecer na televisão, o tempo é ditado pela metralhadora de cortes dos spots publicitários, ele é escasso, é preciso correr, editar muito rápido, não deixar nenhuma pausa ou intervalo de silêncio. Cada segundo, em televisão, vale muito dinheiro. A maior vítima é o personagem Carlo Giordano, que nunca consegue responder a nenhuma pergunta do entrevistador, pois o tempo de Cinico TV já acabou. Mas, contraditoriamente, há enormes sequências em que nada acontece, programas inteiros em que se vê apenas um personagem cuspindo sobre si próprio, ou comendo freneticamente sem parar, até vomitar em direção à câmera. Tudo é muito rápido, mas de repente tudo para e não há mais nada a ver ou ouvir. É como se Cinico quisesse, em alguns momentos mais privilegiados, colocar um "freio" na televisão, barrar o fluxo, em nome de uma oportunidade de reflexão.

\section{Dois cinéfilos na televisão}

Se Cinico pode ser visto como uma paródia da televisão, o programa não fica apenas nisso. Há alguma coisa a mais que tem a ver com suas qualidades intrínsecas enquanto uma obra de arte audiovisual. Cinéfilos declarados, além de muita experiência no cinema ${ }^{5}$, Ciprì e Maresco trazem para a televisão toda uma experiência de visualidade que nasceu com o cinema, como é 0 caso do preto e branco, da profundidade de campo, do esmero nos enquadramentos, do tratamento plástico da imagem e do plano contemplativo, sem efeitos. Nesse sentido, são um pouco subversivos com relação ao que se supõe ser uma estética "específica" da televisão e que tem sido definida como: a ênfase no primeiro plano, a imagem "chapada" e sem profundidade, o quadro híbrido e repleto de efeitos de superposição, a cor quente e pop e assim por diante. Cinico, quando aparece na tela de televisão, tem um ar um tanto démodé, parece um filme velho dos anos 1930 ou 40, com uma estética marcadamente cinematográfica, mas já com rupturas experimentais, lembrando o primeiro Buñuel, ou Maya Deren, Brakhage, Godard e Pasolini. Desde o início, a paixão que unia Ciprì e Maresco era o cinema, sobretudo o cinema experimental, mas os recursos a que tinham acesso na empobrecida Palermo eram apenas as câmeras de vídeo da TVM e a possibilidade de exibir na televisão. Por que então não combinar as duas coisas? Por que não assumir uma técnica e uma estética da 
televisão, mas trazendo para dentro desse meio uma sensibilidade que 0 cinema destilou durante mais de cem anos? Evidentemente, os recursos expressivos da televisão não foram rechaçados; há todo um trabalho com 0 "grão" videográfico, com as distorções eletrônicas dos sinais de imagem e som, uma ênfase na fragmentação, na serialidade e na interrupção do programa para os intervalos. Foi o que fizeram também Rosselini, Bergman, Godard, Kluge, entre outros cineastas que tiveram uma passagem pela televisão; mas com Ciprì e Maresco essa investida é sistemática e sem nenhum tipo de concessão, apontando para algo assim como uma televisão experimental. Eis um depoimento significativo de Maresco (2009):

Eu não me interessava por vídeo ou por eletrônica, mas por razões que já disse, de fazer da necessidade uma virtude, utilizamos 0 vídeo como se fosse cinema. Daí precisamente o uso do preto e branco, o uso de alguns dégradés e 0 uso de filtros e de algumas lentes. Mas o que caracterizou Cinico TV foi a utilização de um enquadramento essencialmente cinematográfico. Com o uso de dégradés e filtros, e com o preto e branco, buscamos recriar o grande preto e branco do cinema clássico.

Mas ainda que Ciprì e Maresco ressaltem seu parentesco com o cinema, essa vinculação não é ingênua, nem isenta de crítica. Frequentemente o cinema é por eles utilizado como matéria de burla e paródia, como, por exemplo, no episódio L'Alba del Killer, no qual os personagens Giudice, Tirone e Martino espancam Pietro Giordano com as coronhas de seus revólveres, exatamente como os macacos o fizeram com seus ossos no começo de 2001, a Space Odissey, inclusive ao som da mesma música, Also Sprach Zaratustra, de Richard Strauss. Como reconhece Maresco (2009):

Ironizamos, fizemos muita ironia citando aquele cinema. Porque é óbvio que citávamos esse cinema como em uma composição de jazz. No jazz existe o hábito de citar. Então, tínhamos um gosto pela citação.

Aparte isso, Ciprì e Maresco são muito

frequentemente citados na Itália como vinculados ao movimento italiano da vídeo-arte (LISCHI, 1996, p. 29; SOSSAI, 2002, p. 111-113). De fato, a crítica implacável à televisão, mas de dentro da própria televisão e com os recursos da televisão, a subversão dos recursos expressivos desse meio e, sobretudo, a temática apocalíptica aproximam Cinico TV de uma boa parte da produção italiana de vídeo-arte. Nos primeiros trabalhos que Ciprì e Maresco fizeram para a TVM há programas mais conceituais e mais próximos da arte do vídeo do que do cinema, como, por exemplo, os cenários desolados e silenciosos da cidade de Palermo, onde as ruínas vibram por um efeito eletrônico resultante de uma panorâmica rápida da câmera de vídeo. Ou um clipe de jazz em que aparece um homem sentado sobre um muro, lendo um jornal, enquanto a imagem vai desaparecendo devido a um acúmulo de manchas sobre o quadro. Os próprios realizadores admitem essa filiação, quando afirmam:

Nós trouxemos para a televisão nossa sensibilidade de visionários, de cinéfilos. Por que não 
levar para lá a pesquisa da imagem, o sentido do enquadramento, a composição? Nós trouxemos a contaminação, a possibilidade de inserir o cinema, o vídeo e a vídeo-arte no interior do palimpsesto televisivo. Isso porque cremos que também é possível experimentar fazendo televisão, pois esta não é só lixo. (apud MORREALE, 2003, p. 78).

\section{Os protagonistas principais}

0 elenco de Cinico TV é formado por um grupo de atores não profissionais, pessoas comuns da comunidade de Palermo que se dispuseram a interpretar os papéis mais excêntricos e degradantes. Alguns têm fisionomia grotesca, outros são cheios de tiques e espasmos, outros simplesmente fogem dos estandartes geralmente utilizados na televisão. Eles formam um bestiário aterrorizador, ainda que irônico e cômico, que mostra os abismos infernais nos quais um ser humano pode afundar. No dizer de Sossai (2002, p. 111), eles são flagrados pela câmera,

[...] na imobilidade de uma condição de transe místico, no ato de desabafo das pulsões de tipo maníacas, ou de uma fisiologia elementar e animalesca. 0 diálogo perde a sua primeira função comunicativa para se transformar num longo interrogatório e numa mortificante autodefesa.

Francesco Tirone representa o ciclista, personagem de um fortíssimo acento plebeu, mas um dos poucos que falam no programa, além de também cantar (de modo horroroso). Interpreta também o Mafiaman, o "super-herói" que ajuda não se sabe se os bons ou os maus, porque em Cinico TV a fronteira entre ambos é indiscernível. Quase sempre conclui os sketches em que aparece com a frase que 0 caracteriza: "Ah! Ah! Siamo davero pietosi!" (Ah! Ah! Somos verdadeiramente piedosos).

Pietro Giordano é o mais lamentável de todos. Pode representar um corcunda, um estuprador, um voyeur, um excremento, um preservativo usado, o dono de um cachorro morto, uma bomba esperando a chegada de um magistrado, 0 presidente da associação dos italianos fracasados, o ridículo "Tarzan de Palermo", ou simplesmente um miserável mudo, que passa seus dias chorando e cuspindo sobre a própria cara.

Marcello Miranda é o mais rígido e silencioso, a personificação da desolação mais absoluta. Não fala, não se mexe, não olha para ninguém, nem para lugar algum. Tem os braços rendidos para baixo e os ombros arqueados. Quando alguém lhe cospe na cara, ele apenas pega seu lenço e se limpa, voltando à prostração anterior. É aquele que os irmãos consideraram imbecilizado pelos programas de Berlusconi e que, por essa razão, pediram indenização. Já tentou suicídio com uma bomba de gás.

Carlo Giordano é o mais velho do grupo. Aparece às vezes com um punhado de balões de ar, sempre estourados por uma mão anônima que vem de fora do quadro com um alfinete. Seu sonho é poder voar, mas nunca tem balões suficientes. Gosta de contar piadas indecentes e de ver revistas pornográficas, e quando começa a rir, ri como um alucinado e só para quando a voz 
do entrevistador, fora de campo, lhe faz alguma pergunta. A pergunta termina sempre com a frase: "O sol está se pondo e temos apenas um minuto." Mas Carlo Giordano nunca consegue terminar a sua resposta, pois a televisão o coloca fora do ar no meio da frase.

Giovanni Logiudice é um cantor lírico e aparece quase sempre em uma espécie de simulacro de videoclipe, cantando canções cafonas e fazendo gestos estereotipados, lembrando mais um calouro de programa de auditório, sempre em meio aos cenários desolados e aos escombros.

Giuseppe Paviglianiti é um semi-anão gordo, que aparece quase sempre semi-nu, mostrando a barriga obscena, frequentemente comendo e bebendo sem parar, obviamente peidando, com um olhar perdido no horizonte. Há um especial de Cinico TV, um dos mais escatológicos, em que ele come desvairadamente durante quase uma hora, arrota e vomita diante da câmera, e volta novamente a comer.

\section{Giuseppe Fillangieri é o personagem} mais jovem, mas já com óculos de lentes exageradamente grossas. É um místico, só fala (quando fala) de coisas do além, mas vive permanentemente amedrontado e intimidado pelas perguntas indiscretas da voz fora de campo. Quase nunca consegue responder a nenhuma pergunta, porque gagueja e fica com a voz bloqueada. Quando fala, é sempre com uma voz frágil, tímida e quase inaudível.
Os irmãos Abbate, Franco e Rosolino Abbate, são funcionários de uma funerária e preparam os corpos dos inúmeros mortos diários de Palermo para os enterros. São ridículos, falam os dois ao mesmo tempo e repetem sempre os mesmos discursos, com a voz exageradamente alta, como se estivessem gritando de histeria. 0 único problema deles é quando precisam preparar um cadáver feminino, pois ficam constrangidos.

\section{Considerações finais}

Cinico TV foi, enfim, uma demonstração de que a televisão pode ser outra coisa, pode ser experimental e criativa, pode arriscar-se em direção a um audiovisual de insubmissão ao gosto padronizado, um audiovisual de expressão de inquietudes não catalogadas, de modo a provar que há também vida inteligente na tela pequena. Os autores defenderam a ideia de que a demanda comercial e 0 contexto industrial não inviabilizam necessariamente a criação artística, a menos que identifiquemos a arte com 0 artesanato ou com a aura do objeto único. A arte de cada época é feita não apenas com os meios, os recursos e as demandas dessa época, mas também no interior dos modelos econômicos e institucionais nela vigentes, mesmo quando essa arte é francamente contestatória em relação a eles. Por mais severa que possa ser a nossa crítica à indústria do entretenimento de massa, não se pode esquecer que essa indústria não é um monólito. Por ser complexa, ela está repleta de contradições internas e é nessas suas 
brechas que os verdadeiros criadores podem penetrar para propor alternativas qualitativas.

Assim, não há nenhuma razão porque, no interior da indústria do entretenimento, não possam despontar produtos - como é o caso de Cinico TV - que em termos de qualidade, originalidade e densidade significante rivalizem com a melhor arte "séria" de nosso tempo. Não há também nenhuma razão porque esses produtos qualitativos da comunicação de massa não possam ser considerados as verdadeiras obras criativas do nosso tempo, sejam elas consideradas arte ou não.

\section{Referências}

FAVA, Vladimir. Il libro di Blob. Torino: Nuova Eri, 1993. GRASSO, Aldo. Storia della televisione italiana. Milano: Garzanti, 1992.

GUEZZI, Enrico. Il mezzo è l'aria. Milano: Bompiani, 1997.

Paura e desiderio: cose (mai) viste. Milano:

Bompiani, 2003.

LISCHI, Sandra. Cine ma video. Pisa: ETS, 1996.

MARESCO, Franco. Franco Maresco: entrevista. [19 set. 2009]. Entrevistadora: Marta Lucía Vélez. Palermo: s. n., 2009.

MORREALE, Emiliano. Ciprì e Maresco. Alessandria: Falsopiano, 2003.

SOSSAI, Maria Rosa. Artevideo: storie e culture del video d'artista in Italia. Milano: Silvana Editoriale, 2002. 
Television after the hecatomb

\section{Abstract:}

An old question, that returns to the times of Adorno, refers to the possibility of television turning out to be a space of experimentation and creativity. The Italian program Cinico TV, by Ciprì and Maresco, gives a radical answer to that question. Without making any concessions to the institutional standards and industrial television, Cinico brings to the scene, in a gloomy black and white, a world that looks like the day after a nuclear hecatomb, peopled by a gallery of absurd characters, somewhat scatological, with a Sicilian and plebeian accent almost unintelligible, in a setting of ruins, dejections, and unfinished and abandoned buildings. The program is conceived as a pirate intervention into television. This article discusses the decline of Italian television and the vital answer that Ciprì and Maresco give to it. Cinico TV was a demonstration that television can be something else, it can risk itself towards an audiovisual insubordination to standard tastes, an audiovisual expression of concerns not catalogued, in order to prove that there is intelligent life in the small screen.

\section{Keywords:}

Cinico TV. Experimental television. Television and art. Italian television.

\section{La televisión después de la hecatombe}

\section{Resumen:}

Una vieja cuestión, que se remonta a los tiempos de Adorno, se refiere a la posibilidad de la televisión como un espacio de experimentación y creatividad. El programa italiano Cinico TV, de Ciprì y Maresco, da una respuesta radical a esa pregunta. Sin hacer ninguna concesión a los patrones institucionales e industriales de la televisión, Cinico pone en escena, en un blanco y negro lúgubre, un mundo que parece el day after de una hecatombe nuclear, habitado por una galería de personajes absurdos, un tanto escatológicos, con un acento siciliano y plebeyo casi ininteligible, en un escenario en ruinas, deshechos y predios inacabados y abandonados. El programa es concebido como una intervención pirata en la televisión. El artículo discute la decadencia de la televisión italiana y la respuesta vital que le dan Cipri y Maresco. Cinico TV fue una demostración de que la televisión puede ser otra cosa, que puede arriesgarse hacia un audiovisual no sumiso a los patrones, un audiovisual de expresión de inquietudes no catalogadas, para probar que hay también vida inteligente en la pequeña pantalla.

\section{Palabras clave:}

Cinico TV. Televisión experimental. Televisión y arte. Televisión italiana. 


\section{Expediente}

A revista E-Compós é a publicação científica em formato eletrônico da Associação Nacional dos Programas de Pós-Graduação em Comunicação (Compós). Lançada em 2004, tem como principal finalidade difundir a produção acadêmica de pesquisadores da área de Comunicação, inseridos em instituições do Brasil e do exterior.
E-COMPÓS I www.e-compos.org.br I E-ISSN 1808-2599

Revista da Associação Nacional dos Programas de Pós-Graduação em Comunicação. Brasília, v.13, n.2, maio/ago. 2010

A identificação das edições, a partir de 2008 passa a ser volume anual com três números.

\section{CONSELHO EDITORIAL}

Afonso Albuquerque

Universidade Federal Fluminense, Brasil

Alberto Carlos Augusto Klein

Universidade Estadual de Londrina, Brasi

Alex Fernando Teixeira Primo

Universidade Federal do Rio Grande do Sul, Brasil

Alfredo Vizeu

Universidade Federal de Pernambuco, Brasi

Ana Carolina Damboriarena Escosteguy

Pontifícia Universidade Católica do Rio Grande do Sul, Brasil

Ana Silvia Lopes Davi Médola

Universidade Estadual Paulista, Brasil

André Luiz Martins Lemos

Universidade Federal da Bahia, Brasil

Ângela Freire Prysthon

Universidade Federal de Pernambuco, Brasil

Antônio Fausto Neto

Universidade do Vale do Rio dos Sinos, Brasil

Antonio Carlos Hohlfeldt

Pontifícia Universidade Católica do Rio Grande do Sul, Brasil

Arlindo Ribeiro Machado

Universidade de São Paulo, Brasil

César Geraldo Guimarães

Universidade Federal de Minas Gerais, Brasil

Cristiane Freitas Gutfreind

Pontifícia Universidade Católica do Rio Grande do Sul, Brasil

Denilson Lopes

Universidade Federal do Rio de Janeiro, Brasil

Eduardo Peñuela Cañizal

Universidade Paulista, Brasi

Erick Felinto de Oliveira

Universidade do Estado do Rio de Janeiro, Brasil

Francisco Menezes Martins

Universidade Tuiuti do Paraná, Brasil

Gelson Santana

Universidade Anhembi/Morumbi, Brasil

Goiamérico Felício

Universidade Federal de Goiás, Brasil

Hector Ospina

Universidad de Manizales, Colômbia

Herom Vargas

Universidade Municipal de São Caetano do Sul, Brasil

leda Tucherman

Universidade Federal do Rio de Janeiro, Brasil

Itania Maria Mota Gomes

Universidade Federal da Bahia, Brasil

Janice Caiafa

Universidade Federal do Rio de Janeiro, Brasil

Jeder Silveira Janotti Junior

Universidade Federal da Bahia, Brasil
João Freire Filho

Universidade Federal do Rio de Janeiro, Brasil

John DH Downing

University of Texas at Austin, Estados Unidos

José Luiz Aidar Prado

Pontifícia Universidade Católica de São Paulo, Brasil

José Luiz Warren Jardim Gomes Braga

Universidade do Vale do Rio dos Sinos, Brasi

Juremir Machado da Silva

Pontifícia Universidade Católica do Rio Grande do Sul, Brasil

Lorraine Leu

University of Bristol, Grã-Bretanha

Luiz Claudio Martino

Universidade de Brasília, Brasil

Maria Immacolata Vassallo de Lopes

Universidade de São Paulo, Brasil

Maria Lucia Santaella

Pontifícia Universidade Católica de São Paulo, Brasil

Mauro Pereira Porto

Tulane University, Estados Unidos

Muniz Sodre de Araujo Cabral

Universidade Federal do Rio de Janeiro, Brasil

Nilda Aparecida Jacks

Universidade Federal do Rio Grande do Sul, Brasil

Paulo Roberto Gibaldi Vaz

Universidade Federal do Rio de Janeiro, Brasil

Renato Cordeiro Gomes

Pontifícia Universidade Católica do Rio de Janeiro, Brasil

Ronaldo George Helal

Universidade do Estado do Rio de Janeiro, Brasil

Rosana de Lima Soares

Universidade de São Paulo, Brasil

Rossana Reguillo

Instituto Tecnológico y de Estudios Superiores do Occidente, México

Rousiley Celi Moreira Maia

Universidade Federal de Minas Gerais, Brasil

Samuel Paiva

Universidade Federal de São Carlos, Brasil

Sebastião Albano

Universidade Federal do Rio Grande do Norte, Brasil

Sebastião Carlos de Morais Squirra

Universidade Metodista de São Paulo, Brasil

Simone Maria Andrade Pereira de Sá

Universidade Federal Fluminense, Brasi

Suzete Venturelli

Universidade de Brasília, Brasil

Valério Cruz Brittos

Universidade do Vale do Rio dos Sinos, Brasil

Veneza Mayora Ronsini

Universidade Federal de Santa Maria, Brasil

Vera Regina Veiga França

Universidade Federal de Minas Gerais, Brasil

COMISSÃO EDITORIAL

Felipe da Costa Trotta I Universidade Federal de Pernambuco, Brasi Rose Melo Rocha I Escola Superior de Propaganda e Marketing, Brasil Adriana Braga I Pontifícia Universidade Católica do Rio de Janeiro, Brasil

CONSULTORES AD HOC

Roseli Figaro I Universidade de São Paulo, Brasil

Miguel Serpa Pereira I Pontifícia Universidade Católica do Rio de Janeiro, Brasi João Maia I Universidade do Estado do Rio de Janeiro, Brasil Paulo Cunha Filho I Universidade Federal de Pernambuco, Brasi

Benjamim Picado I Universidade Federal Fluminense, Brasi Josimey Silva I Universidade Federal do Rio Grande do Norte, Brasil

EDIÇÃO DE TEXTO E RESUMOS I Everton Cardoso

TRADUÇÕES PARA 0 INGLÊS I Lisa Earl Castillo e Sabrina Gledhill EDITORAÇ̃̃ ELETRÔNICA I Roka Estúdio
COMPOS I wWw.compos.org.br

Associação Nacional dos Programas de Pós-Graduação em Comunicação

Presidente

Itania Maria Mota Gomes

Universidade Federal da Bahia, Brasil

itania@ufba.br

Vice-presidente

Julio Pinto

Pontifícia Universidade Católica de Minas Gerais, Brasil juliopinto@pucminas.br

Secretária-Geral

Ana Carolina Escosteguy

Pontifícia Universidade Católica do Rio Grande do Sul, Brasil carolad@pucrs.br 